\title{
Experimental study of a new sutureless intraluminal graft with a shape-memory alloy ring
}

\begin{abstract}
A new sutureless intraluminal graft has been developed with a ring made of a titanium-nickel shape-memory alloy. The diameter of the ring can be reversibly reduced by compression in $4^{\circ} \mathrm{C}$ normal saline solution and recovers its original shape in $38^{\circ} \mathrm{C}$ physiologic saline solution during insertion in the aorta. The new graft was implanted in nine dogs and was evaluated histologically and angiographically at various intervals from 15 to 90 days. No complications, such as dislodgment, aortic rupture, stenosis, or aneurysmal dilation, were observed. The component of the shape-memory ring allows the graft to be introduced and secured in place easily. The function of this ring is better than that of the rigid ring. (J THORAC CARDIOVASC SURG 1994;107:191-5)
\end{abstract}

Chuanrui Yang, MD, Yanqing Sun, MD, Peiqing Dong, MD, and Huazhong Wang, MD, Beijing, China

Us of sutureless intraluminal vascular grafts has become an accepted means of replacing the thoracic and abdominal aorta. ${ }^{1,2}$ Primary benefits of this technique are the decreased crossclamp time and the reduction of bleeding from suture lines. However, placement of the largest graft possible in a small or diseased aorta is often difficult. For this reason, a sutureless intraluminal graft with a compressible ring was developed that could be placed within the aortic lumen with ease and then expanded to the aortic diameter. ${ }^{3}$ The results in healthy canine aortas were encouraging; however, use of the flexible ring in a friable, atherosclerotic aorta could result in dislodgment. In addition, placement of a securing tie around the spool resulted in undesirable compression of the luminal diameter. To improve this prototype, Matsumae and Lemole ${ }^{4}$ developed a graft that is flexible during insertion but becomes rigid after placement and expansion in the aorta to promote graft diameter and prevent dislodgment. Recently, we developed a new

From the Department of Thoracic and Cardiovascular Surgery, Beijing Heart, Lung and Blood Vessel Medical Center and Anzhen Hospital Andingmenwai, Capital Medical University, Beijing, China.

Received for publication March 25, 1993.

Accepted for publication May 17, 1993.

Address for reprints: Chuanrui Yang, MD, Department of Thoracic and Cardiovascular Surgery, Beijing Heart, Lung and Blood Vessel Medical Center and Anzhen Hospital Andingmenwai, Beijing 100029, China.

Copyright $\odot 1994$ by Mosby-Year Book, Inc.

$0022-5223 / 94 \$ 1.00+.10 \quad 12 / 1 / 49684$ sutureless intraluminal graft with a titanium-nickel shape-memory alloy ring that is flexible during insertion and recovers its original shape after placement in the aorta, providing a technical advantage compared with the rigid ring previously described.

\section{Materials and methods}

Graft composition and operation. The ring portion of the graft is made of a flat titanium-nickel shape-memory alloy 13 to $15 \mathrm{~mm}$ in diameter and $0.25 \mathrm{~mm}$ thick. The diameter can be reduced to 7 to $8 \mathrm{~mm}$ by formation in $4^{\circ} \mathrm{C}$ normal saline solution, and it can recover its original size in $38^{\circ} \mathrm{C}$ physiologic saline solution (Fig. 1). Rings are placed at both ends of a knitted Dacron graft 12 to $14 \mathrm{~mm}$ in diameter and are covered with cuffs of the Dacron fabric that are turned over on themselves at both ends (Fig. 2). The safe, knitted Dacron covering does not change the behavior of the titanium-nickel shape-memory alloy ring.

Perioperative medications. Aspirin $300 \mathrm{mg}$ and dipyridamole $50 \mathrm{mg}$ were administered orally once daily starting 3 days before operation and continuing for 1 month after the operation.

Animal study. Nine mongrel dogs weighing 14.5 to $18.6 \mathrm{~kg}$ were anesthetized with sodium pentobarbital (average dose 40 $\mathrm{mg} / \mathrm{kg}$ ). A posterolateral left thoracotomy was used in all dogs. The pleural cavity was entered through the fourth interspace.

Removal of the rib was unnecessary. Heparin $2 \mathrm{mg} / \mathrm{kg}$ was injected intravenously. The aorta was crossclamped, and a longitudinal incision was made through the designated area. A sutureless device with two rings was autoclaved in 5\% albumin for 5 minutes and was implanted in the descending thoracic aorta of each dog (Fig. 3). After the rings had been folded to a small diameter by hand in $4^{\circ} \mathrm{C}$ normal saline solution, the prosthesis was introduced into the aorta until the proximal and distal spools were covered entirely with aortic tissue. Then, 20 $\mathrm{ml}$ normal saline solution at $38^{\circ} \mathrm{C}$ was injected to the surface 

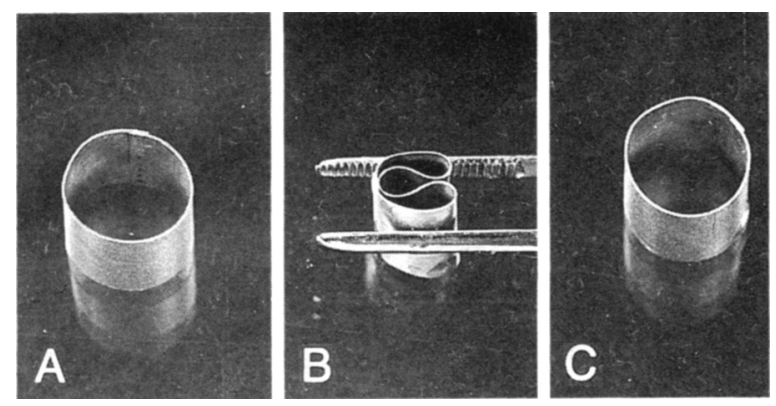

Fig. 1. Schematic drawing of the ring portion of the graft. A, The ring is made of a flat shape-memory alloy with a $15 \mathrm{~mm}$ diameter. B, The ring can be compressed to an $8 \mathrm{~mm}$ diameter in $4^{\circ} \mathrm{C}$ normal saline solution and kept at a smaller diameter during aortic insertion. $\mathbf{C}$, The ring can recover its original shape after $20 \mathrm{ml}$ normal saline solution at $38^{\circ} \mathrm{C}$ is injected onto its surface.

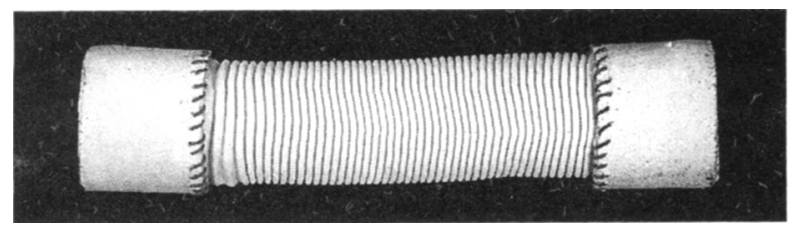

Fig. 2. New sutureless intraluminal graft with titanium-nickel shape-memory alloy ring is placed at both ends of a knitted Dacron graft and covered with cuffs of Dacron fabric that are turned over on themselves at both ends.

Table I. Summary of experience

\begin{tabular}{ccc}
\hline Dog No. & $\begin{array}{c}\text { Crossclamp } \\
\text { time (min) }\end{array}$ & $\begin{array}{c}\text { Follow-up } \\
\text { period (days) }\end{array}$ \\
\hline 1 & 4 & 15 \\
2 & 4 & 23 \\
3 & 2 & 32 \\
4 & 3 & 39 \\
5 & 2 & 48 \\
6 & 3 & 57 \\
7 & 3 & 65 \\
8 & 2 & 76 \\
9 & 3 & 90 \\
\hline
\end{tabular}

of the prosthesis. At this point, the rings recovered their original shape and attached themselves to the vessel wall immediately. Two circular ties of Dacron fabric, which were $5 \mathrm{~mm}$ wide and $1 \mathrm{~mm}$ thick, were placed around the ring and secured. Air was evacuated with a needle inserted into the prosthesis. Heparin was reversed with intravenous protamine on a 1:1 basis. Chest tubes were inserted and secured. The thoracotomy incision was then closed. In all studies, animals received humane care in compliance with the "Principles of Laboratory Animal Care" formulated by the National Society for Medical Research and the "Guide for the Care and Use of Laboratory Animals" prepared by the National Academy of Sciences and published by

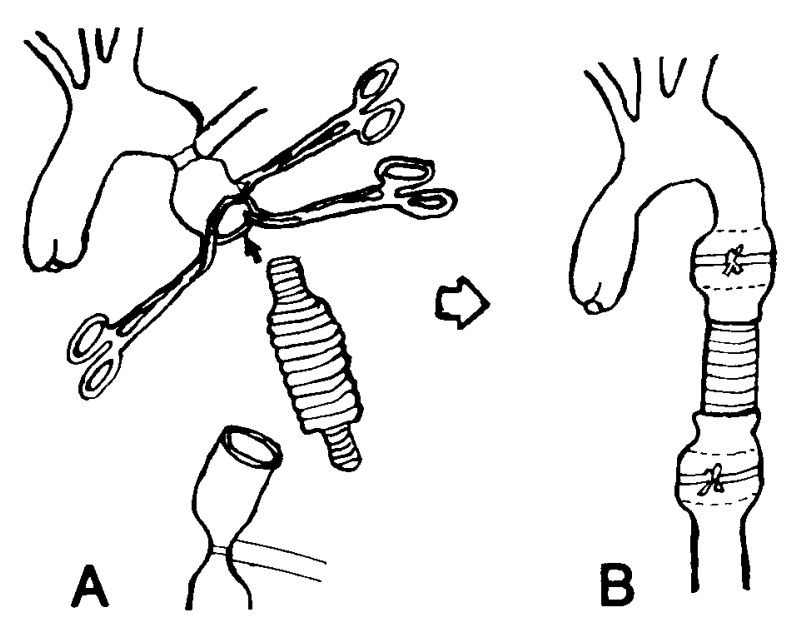

Fig. 3. Implantation procedure. A, With the ring compressed in $4^{\circ} \mathrm{C}$ normal saline solution and kept at a smaller diameter ( 7 to $8 \mathrm{~mm}$ ), the graft is introduced into the aorta until the proximal and distal spools are covered entirely with aortic tissue. B, After insertion to the appropriate level, $20 \mathrm{ml}$ normal saline solution at $38^{\circ} \mathrm{C}$ was injected onto its surface until the rings recovered their original shape. The spools then were secured with two wide circular ties.

the National Institutes of Health (NIH Publication No. 86-23, revised 1985).

Aortograms performed on the day of death were evaluated for the presence of pseudoaneurysms, status of the anastomoses, and patency of the graft. Aortic specimens were processed for histologic examination when dogs were killed at variable intervals.

\section{Results}

In this experiment, the average aortic clamping time was 2.9 minutes. No marked bleeding from the anastomosis occurred. No deaths occurred from complications of the titanium-nickel shape-memory alloy ring.

Nine dogs were killed at intervals between 15 days and 90 days (Table I). Aortograms showed that all grafts were patent and that stenosis, dilation at the anastomosis, and flow surface irregularities on the anastomotic line (Fig. 4) did not occur.

At autopsy, no cases of spool dislodgment, pseudoaneurysm formation, or rupture were observed. The inner surface of the graft was covered with neointima, and the outer surface of the spools was tightly adherent to the host aortic wall in all cases (Fig. 5). The thickness of the media was reduced about $50 \%$ by the expansion pressure of the ring and the compression of the tie and at the point of the tie knot, and the thickness of the media was reduced about $70 \%$ to $80 \%$ by the pressure of the tie knot in three cases. These changes were evident within 1 month of the operation and did not develop further. The Dacron flat ties 


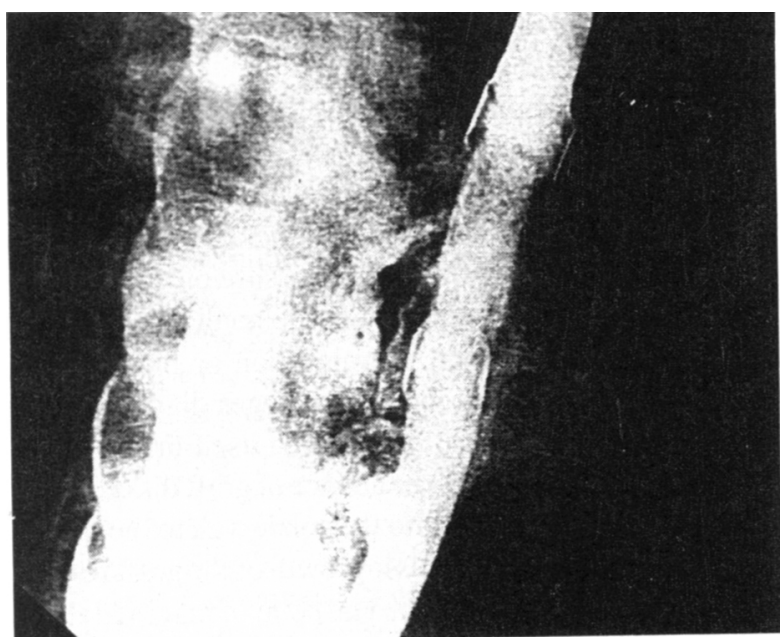

Fig. 4. Aortogram 90 days after implantation shows neither stenosis nor dilation at the anastomosis.

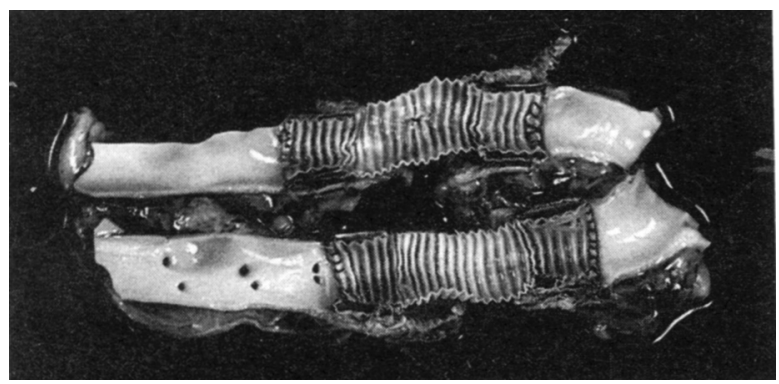

Fig. 5. Macroscopic findings of internal lumen. The graft was covered with neointima, and anastomotic lines were smooth. No detachment of the ring was observed 90 days after implantation.

caused no necrosis of the aortic wall (Fig. 6) and no erosion into the aortic wall to the spools. In the outer and the inner fourth of the aortic wall compressed by the ring, the number of smooth muscle cell nuclei was less than in normal aortic wall tissue (Fig. 7). At the border between the aortic wall just beyond the ring and the aortic wall overlying the ring, the elastic fibers were tortuous, but erosion was not observed.

\section{Discussion}

Since the first application of the sutureless intraluminal graft in the dissection of aortic aneurysm in 1978 by Dureau et al. ${ }^{5}$ and Ablaza, Gosch, and Grana, ${ }^{6}$ it has been widely used in reconstruction of the thoracic and abdominal aorta.

Reports ${ }^{7}$ advocating the use of two sutureless devices have documented the potential benefit of sutureless grafts in the aortic arch. It was found that the sutureless device

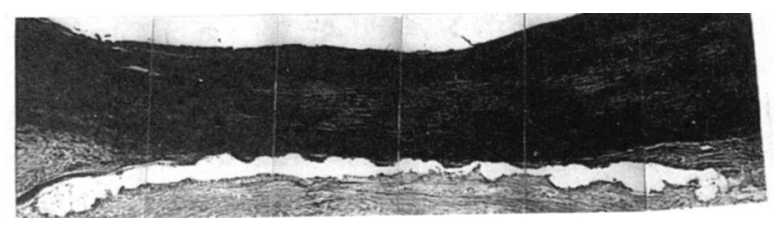

Fig. 6. Longitudinal section of aorta 90 days after operation. Elastic fibers are stained black. The area of compression by the silk tie and the ring is shown: the pressure of the tie, which is 5 $\mathrm{mm}$ wide and $1 \mathrm{~mm}$ thick, on the aorta wall is reduced so that the continuity of the aortic wall was preserved well (Verhoeff staining, original magnification $\times 100$ ).

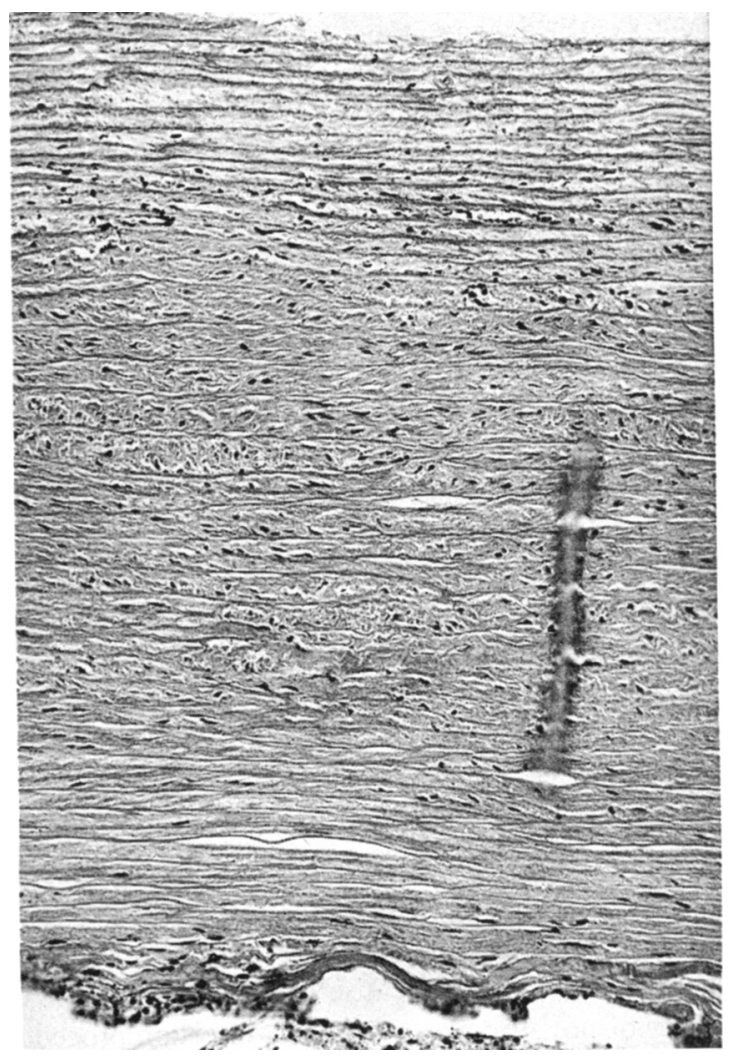

Fig. 7. Longitudinal section of aortic wall 30 days after operation. Outer and inner fourth of the aortic wall was compressed by the spool, and the number of the smooth muscle cell nuclei in this area was less than that in normal aortic wall tissue (hematoxylin and eosin staining, original magnification $\times 200$ ).

was preferable because it is created more rapidly and allows more versatility in adapting the graft to the pathologic condition encountered at operation. ${ }^{8}$ Most of the recent interest in aortic surgery has been focused on the attempt to diminish the prevalence of complications related to ischemia of the distal organ, and much emphasis has been placed on the need for a simplified and rapid 
surgical technique that would prevent such complications. ${ }^{9-11}$ We believe that one of the primary causative factors of postoperative paraplegia that can be controlled is intraoperative ischemic time. In this study, we were able to perform the operation with a minimal crossclamp time. The average aortic clamping time was 2.9 minutes.

The traditional sutureless graft has the following advantages: (1) aortic clamp time is shortened because no suturing is necessary ${ }^{3}$; (2) no bleeding from the anastomosis occurs because of fixation by the circular tie $\mathrm{e}^{3}$; and (3) it offers versatility in the construction of composite grafts that suit the aortic disease encountered at operation. ${ }^{12}$ However, it also has the following disadvantages $^{3,4}$ : (1) the degeneration of the host aorta induced by tape fixation may cause migration of the ring or wall rupture of the aorta at the ring; (2) the predicted diameter of the graft is sometimes too large to be inserted in the aorta because of reduction of the aortic diameter by clamping; (3) stenosis sometimes occurs at the anastomosis; (4) tape fixation around the ring is sometimes difficult because marked atherosclerotic change of the aorta makes the position of the ring unclear; and (5) use of the elastic ring in a friable, atherosclerotic aorta could result in dislodgment. To eliminate these problems, we developed the titanium-nickel shape-memory alloy ring. The titanium-nickel shape-memory alloy ring, reduced in diameter by formation in $4^{\circ} \mathrm{C}$ normal saline solution, is intraluminally inserted in the aorta and recovers its original shape by the memory function of the ring at $38^{\circ} \mathrm{C}$. Using this graft, we can overcome the previously mentioned disadvantages, and the titanium-nickel shapememory alloy ring has good biocompatibility. ${ }^{13}$

In this study, the ratio of host aorta to ring was $12.4 \pm 0.8$ to $14.7 \pm 0.9$ (host aorta without clamping; ring before formation), which makes the position of the ring clear before tape fixation. The degeneration of the host aorta did not occur because we used wide ties and the intensity of pressure was small. The insertion procedure of the titanium-nickel shape-memory alloy ring was easier than that of the flexible ring, ${ }^{4}$ which involves ratchets because Lemole's expandable graft required the forcible dilatation of the terminal ring by a clamp that is introduced through a side arm on the graft. In this study, all titanium-nickel shape-memory alloy ring implantations (18 rings) could be performed without difficulty. In clinical cases, ${ }^{14}$ the diameter of the graft that could be inserted was small, and stenosis occurred after implantation. In extreme cases, the graft is attached to the aorta only at the point of tape fixation. ${ }^{4}$ There is little possibility that a titanium-nickel shape-memory alloy rings can cause stenosis because its diameter is larger than that of the host aorta. On aortography, no stenosis was observed at the anastomotic line (Fig. 4).

During the 3-month follow-up, no graft migration, aortic rupture, or pseudoaneurysm formation occurred. However, the changes in the aortic wall under the tie knot were significant. In three cases, the thickness of the media was reduced $70 \%$ to $80 \%$ by the pressure of the tie knot. It is noteworthy that even though the media was pressed very thin by the tie knot, no migration or bleeding occurred. Because the spools have a larger diameter than that of the aorta, the graft can attach itself firmly to the aortic wall, which reduces the chance of graft dislodgment even if the tie knot erodes into the aortic wall to the spools. Over time, significant fibrous ingrowth of the graft results, further reinforcing the repair. The point of maximal stress is the border between the aortic wall just beyond the ring and the aortic wall overlying the ring. ${ }^{4}$ In this section of the aorta, the elastic fiber was tortuous, but no aneurysmal change or rupture was observed in our study. However, more serious complications could take place if the spool is so large that the expansion pressure of the ring exceeds the pressure that the vessel wall can tolerate. ${ }^{4} \mathrm{We}$ believe that the correct diameter proportion of the titanium-nickel shape-memory alloy ring and host aorta is very important, and overexpansion of the spool must be avoided. Many methods are available to expand the utility of the sutureless intraluminal prosthesis in aortic replacement. Composite grafts can be created that vary in length and shape, incorporate different graft materials, and accommodate the aorta and its branches. ${ }^{12}$ Modification of the sutureless prosthesis with titanium-nickel shapememory alloy rings will suit the pathologic condition encountered at operation and allow the quickest repair with the least chance of anastomotic complication.

In conclusion, the titanium-nickel shape-memory alloy ring is flexible during insertion and becomes rigid after placement in the aorta, which allows easier implantation of grafts of suitable size and prevents spool dislodgment and stenosis of the anastomosis. The wider ties do not erode and can avoid the aortic wall as fix ties do. The new graft is suitable for aortic and peripheral arterial reconstruction. Further study of the optimal ratio of host aorta-to-ring is necessary to allow variable spool diameters and facilitate use in human beings.

We thank Shunping Du, Yeuhe Du, Yizhong Tan, Yanping $\mathrm{Li}$, Xeulian $\mathrm{Ma}$, and Chunyan Li for their assistance in the study.

\section{R E F ER E N C ES}

1. Lemole GM, Strong MD, Spagna PM, Karmilowicz NP. Improved results for dissecting aneurysms: intraluminal 
sutureless prosthesis. J THORAC CARDIOVASC SURG 1982; 83:249-55

2. $\mathrm{Oz} \mathrm{MC}$, Ashton $\mathrm{RC}, \mathrm{Oz} \mathrm{M}$, et al. Replacement of the abdominal aorta with a sutureless intraluminal ringed prosthesis. Am J Surg 1989;158:121-6.

3. Matsumae $M$, Uchida $\mathrm{H}$, Teramoto $\mathrm{S}$. An experimental study of new sutureless intraluminal graft with an elastic ring that can attach itself to the vessel wall: a preliminary report. J Vasc Surg 1988;8:38-44.

4. Matsumae $\mathrm{M}, \mathrm{Oz} \mathrm{MC}$, Lemole GM. A flexible sutureless intraluminal graft that becomes rigid after placement in the aorta. J Thorac CARDiovasc Surg 1990;100:787-92.

5. Dureau GV, Villard J, George M, Deliry P, Froment JC, Clermont A. New surgical technique for the operative management of acute dissections of the ascending aorta. $\mathbf{J}$ ThORAC CARDIOVASC SURG 1978;76:385-9.

6. Ablaza SG, Gosch SC, Grana VP. Use of ringed intraluminal graft in the surgical treatment of dissecting aneurysm of the thoracic aorta. J THORAC CardiovasC SURG 1978;76:390-6.

7. Thompson E, Schaff HV. A method of repair of aortic dissection originating in the transverse arch using two sutureless intraluminal prostheses. Arch Surg 1988;123:656-9.
8. Oz MC, Ashton RC, Lemole GM. Aortic replacement with composite grafts created with a sutureless intraluminal ringed prosthesis. J ThORAC Cardiovasc Surg 1990; 100:781-6.

9. Serra AJ, McNicholas KW, Spagna PM, et al. Replacement of the descending thoracic aorta with intraluminal ring graft. Ann Thorac Surg 1989;48:689-92.

10. Koyamada K, Ishikawa S, Yamaki S, et al. Surgical treatment for dissecting aneurysm of the aorta using a double ringed graft. J Cardiovasc Surg 1985;26:488-91.

11. $\mathrm{Oz} \mathrm{MC}$, Ashton $\mathrm{RC}, \mathrm{McNicholas} \mathrm{KW}$, et al. Sutureless ring graft replacement of ascending aorta and aortic arch. Ann Thorac Surg 1990;50:74-9.

12. Oz MC, McNicholas KW, Serra JS, Spagna PM, Lemole GM. Review of Salmonella mycotic aneurysms of the thoracic aorta. J Cardiovasc Surg 1989;30:99-103.

13. Sigwart U, Imbert C, Essinger A, et al. One year of percutaneous coronary stenting [Abstract]. Circulation 1987; 76(Suppl):IV26.

14. Ninomiya J, Yamate N, Koizumi K. Study on surgical treatment of acute aortic dissections. J Jpn Soc Clin Surg 1984;45:1291-7. 